\title{
Transformações de Fases e Medidas de Resistividade Elétrica em Ligas de Titânio
}

\author{
Heitor M. F. da Silva*, Kleanny G. S. de Souza, Rubens C. Junior
}

\section{Resumo}

Este trabalho tem como objetivo analisar o fenômeno de precipitações de fase na liga de titânio do tipo $\beta$ metaestável Ti-5553 por meio de medidas de resistividade elétrica durante tratamento térmico de envelhecimento até $1000^{\circ} \mathrm{C}, \mathrm{com}$ diferentes taxas de aquecimento. Ademais, buscou-se comparar tal método com os resultados obtidos por meio de técnicas de análise térmica.

\section{Palavras-chave:}

\section{Ligas de Titânio, Resistividade Elétrica, Transformações de Fases}

\section{Introdução}

As ligas de titânio vêm sendo cada vez mais estudadas em função de suas propriedades mecânicas únicas. Sabe-se que ao resfriar rapidamente ligas de titânio $\beta$ metaestáveis a partir de altas temperaturas, estas podem reter a fase $\beta$ à temperatura ambiente. Quando, em seguida, são tratadas termicamente, há a precipitação da fase $\alpha$ de forma finamente distribuída na matriz de fase $\beta$. O processo de precipitação da fase $\alpha$ é bastante complexo e influenciado, principalmente, pela existência ou não da fase $\omega$ na matriz e pela temperatura de tratamento térmico, além da taxa de aquecimento.

Tal processo pode ser analisado por meio de estudos de análise térmica ou pela evolução de resistividade elétrica da amostra submetida ao aquecimento, sendo o estudo de resistividade uma alternativa recente, porém eficiente de análise.

Assim, neste trabalho, investigou-se a precipitação da fase a na liga Ti-5Mo-5V-5Al-3Cr-0,5Fe (\% em peso) do tipo $\beta$ metaestável durante processo de envelhecimento usando diferentes taxas de aquecimento por meio de ensaios de resistividade elétrica.

\section{Materiais e Métodos}

Ao se definir a liga Ti-5553 como objetivo de estudo, as amostras foram laminadas até geometria específica que possibilitasse que a corrente elétrica atravessasse os terminais da amostra. Na sequência, as amostras foram solubilizadas, lixadas e polidas. Com as amostras devidamente preparadas iniciaram-se os ensaios de resistividade elétrica. A montagem do ensaio consiste basicamente em 2 terminais em cada extremidade da amostra (método das 4 pontas), sendo 1 de tensão e 1 de corrente, 1 termopar para a medida da variação da temperatura da amostra no forno e do software capaz de captar as variações de tensão e temperatura. $\mathrm{Na}$ análise da evolução de resistividade foram aplicadas diferentes taxas de aquecimento, de forma que fosse possível observar a influência desse parâmetro nas transformações de fases.

\section{Resultados e Discussão}

A figura 1 corresponde a um dos gráficos obtidos por meio do software Origin a partir dos dados coletados no ensaio de resistividade. Nesse gráfico, são colocados tanto o ensaio para uma taxa de aquecimento de $4^{\circ} \mathrm{C}$ por minuto (taxa baixa de aquecimento), quanto o ensaio para uma taxa de $30^{\circ} \mathrm{C}$ por minuto (taxa alta de aquecimento). Nota-se que as curvas apresentam comportamento temperatura pouco abaixo de $400^{\circ} \mathrm{C}$. Para uma taxa elevada de aquecimento o comportamento da resistividade é o esperado para maioria dos materiais (aumento em função do aumento da temperatura). Já em uma taxa baixa ocorre queda na resistividade, tal evento é caracterizado como efeito negativo de dependência da temperatura, atribuído à presença de $\omega_{\text {ath }}$ formado durante rápido resfriamento da fase $\beta^{1}$.

Para a faixa pouco abaixo de 400 até $600^{\circ} \mathrm{C}$, ocorre a precipitação de $\omega$ seguido pelo início de seu desaparecimento para formação de $\alpha^{2}$, na qual ambas curvas exibem aumento de resistividade. Já para temperaturas entre 600 e $800^{\circ} \mathrm{C}$, ambas curvas apresentam queda na resistividade, caracterizando a transformação de $\alpha$ em $\beta^{2}$.

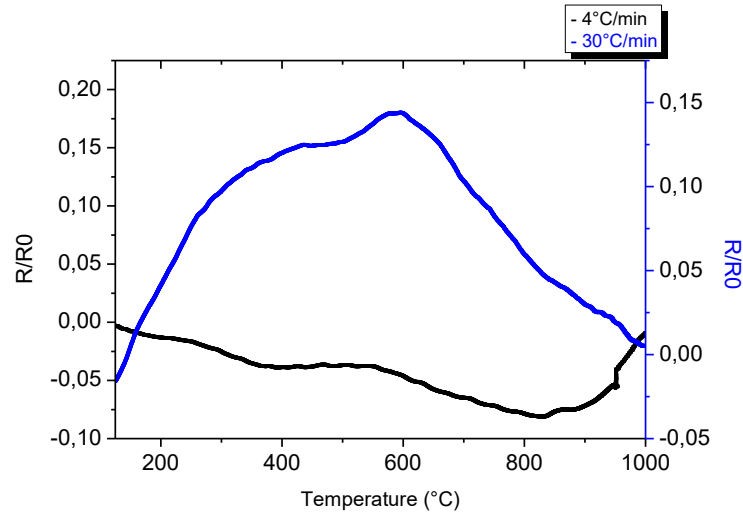

Figura 1. Resistência/resistência elétrica inicial das amostras versus temperatura $\left({ }^{\circ} \mathrm{C}\right)$, usando taxas de aquecimento de 4 e $30^{\circ} \mathrm{C} / \mathrm{min}$.

\section{Conclusões}

O método de caracterização de transformações de fases por meio de ensaios de resistividade elétrica apresentouse como capaz de fornecer as informações esperadas. Observou-se que o aquecimento da amostra permite a precipitação da fase $\omega$ isotérmica, sua dissolução e finalmente, a precipitação da fase $\alpha$ em matriz de fase $\beta$.

${ }^{1}$ M. Ikeda, S. Y. Komatsu, T. Sugimoto and K. Kamei, in Proceedings of the $6^{\text {th }}$ World Conference on Titanium, edited by P. Lacombe et al. (Les Editions de Physique Vol. 1, 1988) p.313.

${ }^{2}$ Contrepois Q, Carton M, Lecomte-Beckers J (2011) Characterization of the $\beta$ phase decomposition in $\mathrm{Ti}-5 \mathrm{Al}-5 \mathrm{Mo}-5 \mathrm{~V}-3 \mathrm{Cr}$ at slow heating rates. Open $\mathrm{J}$ Met $1: 1-11$ 